\title{
Antitumor efficacy of human telomerase reverse transcriptase gene antisense oligonucleotide in pancreatic cancer cells
}

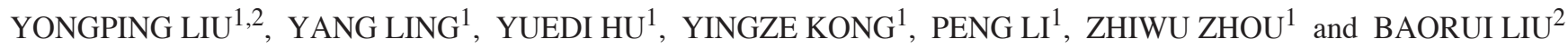 \\ ${ }^{1}$ Clinical Oncology Laboratory, Changzhou Tumor Hospital Affiliated to Medical School of Suzhou University, \\ Huaide Road 44, Changzhou 213001; ${ }^{2}$ Department of Oncology, Drum Tower Hospital, Nanjing University \\ of Traditional Chinese Medicine, Zhongshan Road 321, Nanjing 210008, P.R. China
}

Received November 20, 2008; Accepted March 20, 2009

DOI: $10.3892 / \mathrm{mmr} 00000130$

\begin{abstract}
Human telomerase reverse transcriptase (hTERT) is the key component of telomerase catalytic activity, and is associated with tumorigenesis. Recent evidence suggests that the down-regulation of hTERT could rapidly induce an antiproliferative effect in tumor cells, independent of the telomereelongating function of the enzyme. To test the immediate antitumor efficacy of this down-regulation, antisense oligodeoxynucleotides (AS-ODN) targeting hTERT mRNA were transfected into two human pancreatic cancer cell lines in vitro. In both cell lines, single transfection with AS-ODN decreased the level of hTERT mRNA expression in a dosedependent manner (from 0.05 to $0.2 \mu \mathrm{M}$ ), while transfection with $0.2 \mu \mathrm{M}$ hTERT AS-ODN for $24 \mathrm{~h}$ achieved the maximum down-regulation of hTERT mRNA. Additionally, $0.2 \mu \mathrm{M}$ AS-ODN significantly reduced telomerase activity in the cell lines. However, after the first transfection with $0.2 \mu \mathrm{M}$ ASODN, almost no inhibition of cell proliferation was observed in either of the lines, while multiple consecutive transfections with the same concentration of AS-ODN resulted in a continuous reduction in cell viability, the significant inhibition of colony formation ability and increased cell apoptotic rates. Cell cycle analysis indicated that hTERT AS-ODN mainly arrested the cell cycle at the G0/G1 phase in the cells. The data validate an antisense oligonucleotide approach to hTERT inhibition therapy in pancreatic cancer cells.
\end{abstract}

Correspondence to: Dr Yongping Liu, Clinical Oncology Laboratory, Changzhou Tumor Hospital Affiliated to Medical School of Suzhou University, Huaide Road 44, Changzhou 213001, P.R. China

E-mail: liuyongping026@yahoo.com.cn

Abbreviations: hTERT, human telomerase reverse transcriptase; hTER, human telomerase RNA; FITC, fluoresceine-5-isothiocyanate; FACS, fluoresceine activated cell sorter; AS-ODN, antisense oligodeoxynucleotide; NS-ODN, non-specific oligodeoxynucleotide; TRAP, telemetric repeat amplification protocol

Key words: human telomerase reverse transcriptase, antisense oligonucleotide, pancreatic cancer

\section{Introduction}

Pancreatic cancer is one of the most common causes of cancerrelated mortality in the world, and the incidence of the disease has been steadily increasing. Surgery is the only viable treatment option; however, the cancer is usually diagnosed at a late stage, making tumor resection possible in less than $20 \%$ of patients $(1,2)$. Less than $5 \%$ of all patients diagnosed with pancreatic cancer can expect to survive over 5 years $(2,3)$. Although a great deal of attention has been directed towards the therapeutic treatment of pancreatic cancer, including various adjuvant, neo-adjuvant, locoregional or radio-chemotherapy strategies, the prognosis for patients has not improved significantly, and developing new therapeutic strategies for the treatment of the disease is a top priority.

Telomerase is a ribonucleoprotein enzyme responsible for adding telomeric repeats to the 3 ' ends of chromosomes. The activation of telomerase is thought to be essential to the stabilization of telomere length and for overcoming replicative senescence, which may lead to cellular immortality (4) Telomerase is activated in the vast majority of cancer cells $(5,6)$, including those of pancreatic cancer $(7)$, but is usually repressed in most normal somatic tissue. This suggests that telomerase activation may be a critical step in the progression to cellular immortality and carcinogenesis. The relative tumor selective expression of telomerase has made the enzyme an appropriate target for the development of new anticancer therapies. Telomerase consists of a protein reverse transcriptase, hTERT, and an RNA component, hTR. hTR is ubiquitously expressed in normal cells, while it is the presence of hTERT that confers telomerase activation (8). Without the expression of hTERT, no telomerase activation takes place. Consequently, the elongation and capping of telemeres does not occur. Uncapped or critically shortened telomeres cause cell cycle arrest and/or apoptosis (9). Thus, strategies targeting hTERT may be a more attractive approach to the inhibition of telomerase activity and gene therapy of cancer. A number of methods have been developed to achieve the inhibition of telomerase and cell proliferation in tumor cells, including those based on the use of antisense oligonucleotides (10-14), RNA interference (15-18), peptide nucleic acids (19) or hammerhead ribozymes directed against hTERT (20).

In this study, sequence-specific antisense oligonucleotides targeting the coding region of the protein component 
of human telomerase were designed to examine whether telomerase activity and hTERT mRNA could be inhibited, and to test the antitumor efficacy of this inhibition in pancreatic cancer-derived cells that exhibit different sensitivities to common chemotherapeutics.

\section{Materials and methods}

Design and synthesis of antisense phosphorothiate oligomers. Based on the hTERT gene cDNA sequence (4015 nt; accession no. AF01 5950), the antisense oligonucleotide was designed to be complementary to the translation initiation region of hTERT mRNA. The antisense oligodeoxynucleotide sequence (AS-ODN) was 5'-GGAGCGCGCGGCATCGCGGG-3', and the control non-specific oligodeoxynucleotide sequence (NS-ODN) was 5'-CATTTCTTGCTCTCCACGCG-3', having the same base composition as the antisense oligonucleotide but with a different sequence. The oligodeoxynucleotides were fully phosphorothioated, and were synthesized by Invitrogen (Carlsbad, CA, USA). Their lack of significant interfering homology was validated using BLAST analysis.

Cell culture and transfection. The relatively sensitive pancreatic cancer cell line BxPC-3 and the relatively resistant pancreatic cancer cell line panc-1 were kindly provided by the Center Laboratory of The Second Changzhou People's Hospital, China, and were routinely incubated in DMEM (Gibco BRL) supplemented with 10\% fetal calf serum (Gibco $\mathrm{BRL}), 4 \mathrm{mM}$ glutamine, $50 \mathrm{U} / \mathrm{ml}$ penicillin and $50 \mu \mathrm{g} / \mathrm{ml}$ streptomycin. Cells were grown at $37^{\circ} \mathrm{C}$ in a humidified chamber containing $95 \%$ air and $5 \% \mathrm{CO}_{2}$. The transfection of the oligonucleotides was performed using Oligofectamine ${ }^{\mathrm{TM}}$ Reagent (Invitrogen) according to the manufacturer's instructions. Briefly, the cells were seeded the day before the experiment in different culture plates at various densities per well. On the day of the experiment, they had reached 30-50\% confluence and were transfected with $0.2 \mu \mathrm{M}$ oligofectamine and $0.2 \mu \mathrm{M}$ of oligonucleotides in serum-free DMEM, incubated at $37^{\circ} \mathrm{C}$ for $4 \mathrm{~h}$, and then added to various volumes of growth medium containing $3 \mathrm{x}$ the normal concentration of serum according to the different culture plates without the removal of transfection mixture. Cells were transfected once or every 2-3 days.

Quantitative RT-PCR. The pancreatic cancer cell lines BxPC-3 and panc-1 were harvested with trypsin, washed with PBS and collected by centrifugation at 1,000 rpm for $5 \mathrm{~min}$. Total RNA was extracted using the SV Total RNA isolation system (Promega, Madison, WI, USA) following the manufacturer's protocol. The purity and quality of the total RNA were measured by the Bio-visible spectrophotometer (Enpendorf, Germany), and $1 \%$ agarose gel electrophoresis was used to assess the integrity of the obtained RNA. cDNA with a total volume of $20 \mu \mathrm{l}$ was synthesized using a reverse transcription system containing reverse transcriptase (Promega, Madison, WI, USA) according to the manufacturer's protocol. Real-time quantitative PCR of the target hTERT gene with $\beta$-actin as an internal control was carried out on an icycler iQ Multicolor real-time PCR Detection System (Bio-Rad Laboratories Inc.). The 20- $\mu 1$ PCR reaction mixture was composed of 1x primers and probe mixture (Applied Biosystems, Foster city, CA. Assay IDs: hTERT, Hs99999022_m1; ß-actin, Hs99999903_m1), and 1x Absolute QPCR Mix (ABgene, Surrey, UK). PCR conditions were $50^{\circ} \mathrm{C}$ for $2 \mathrm{~min}$ and $95^{\circ} \mathrm{C}$ for $15 \mathrm{~min}$, followed by 45 cycles at $95^{\circ} \mathrm{C}$ for $15 \mathrm{sec}$ and $60^{\circ} \mathrm{C}$ for $1 \mathrm{~min}$. Relative gene expression quantifications were calculated using the comparative $\mathrm{Ct}$ method with $\beta$-actin as an endogenous control and untreated cells as calibrator. The final results were determined using the $2{ }^{-}{ }^{\Delta \mathrm{CT}}$ formula (21).

Telemetric repeat amplification protocol-silver staining assay. Improved telemetric repeat amplification protocol (TRAP)silver staining assay, based on the protocol introduced by Kim et al (5), was used to assess telomerase activity. Briefly, $20 \mu \mathrm{l}$ PCR products were loaded on $12.5 \%$ polyacrylamide gel and resolved by electrophoresis at $180 \mathrm{EV}$ for $1-2 \mathrm{~h}$. After electrophoresis, the gel was immobilized and rinsed in $10 \%$ glacial acetic acid for $25 \mathrm{~min}$, washed in deionized water for $10 \mathrm{~min}$ and soaked in $0.2 \% \mathrm{AgNO} 3$ for $15 \mathrm{~min}$, then washed in deionized water for $5 \mathrm{~min}$, immobilized and rinsed in $5 \%$ glacial acetic acid for $10 \mathrm{~min}$, and again washed in deionized water for $5 \mathrm{~min}$. Quantitative analysis was performed using a gel imaging system (Bio-Rad, USA) that allowed densitometric (A) evaluation of the digitized image. The amplified telomerase products were of heterogeneous length and created a ladder pattern of bands, each representing the addition of a hexanucleotide telomeric repeat by telomerase. Telomerase activity was quantified by measuring the total density signal of the telomerase ladder bands (A) and the formula: relative telomerase activity=sample A/untreated sample A.

Cell viability assay. Cytotoxicity was determined by the CellTiter 96 AQueous One Solution Cell Proliferation Assay kit (Promega). Briefly, tumor cells growing in log-phase were trypsinized and seeded at $2 \times 10^{3}$ cells/well in 96-well plates and allowed to attach overnight. The medium in each well was replaced with fresh medium or medium with various concentrations of the drug in at least 6 replicate wells every 2 days. On the second day following the first to fifth transfections, one-fifth of the volume of CellTiter 96 AQueous One Solution was added to each well and incubated for an additional $3 \mathrm{~h}$. Absorbance was determined with a microplate reader (Bio-Rad) at $490 \mathrm{~nm}$. The blank control wells were used for zeroing absorbance. Each experiment was allocated ten wells containing drug-free medium as the control. The percentage of cell survival was calculated using background-corrected absorbance as follows: \% cell viability $=100 \times \mathrm{A}_{\text {experimental well }}$ $\mathrm{A}_{\text {untreated control well }}$. Each experiment was performed in triplicate, with representative data presented.

Colony-forming cell assay. Pancreatic tumor cells were transfected 3 times consecutively with AS- or NS-ODN at $0.2 \mu \mathrm{M}$. Subsequently, the transfected and parental cells (300 cells/well) were plated in triplicate in 60-mm Petri dishes. On day 7 , the plates were fixed in $70 \%$ methanol and treated with Giemsa stain. Clonogenic survival was determined by counting the macroscopically visible colonies.

Apoptosis assay. Cell quantification of apoptosic cells was performed using an Annexin-V-fluorescein isothiocyanate 
A

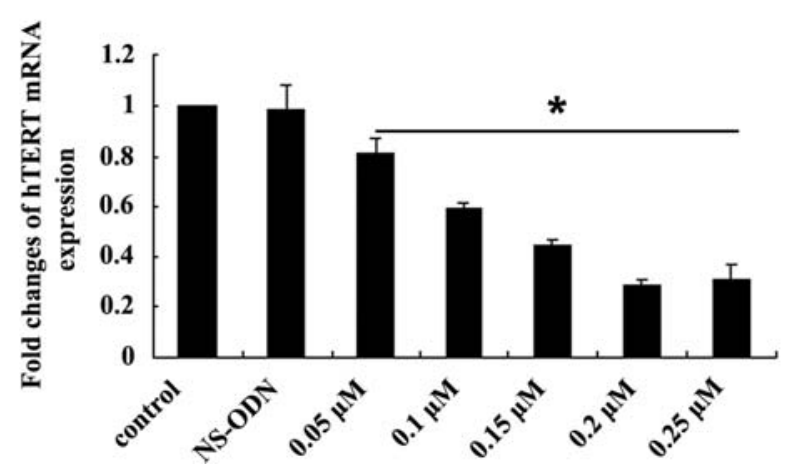

B

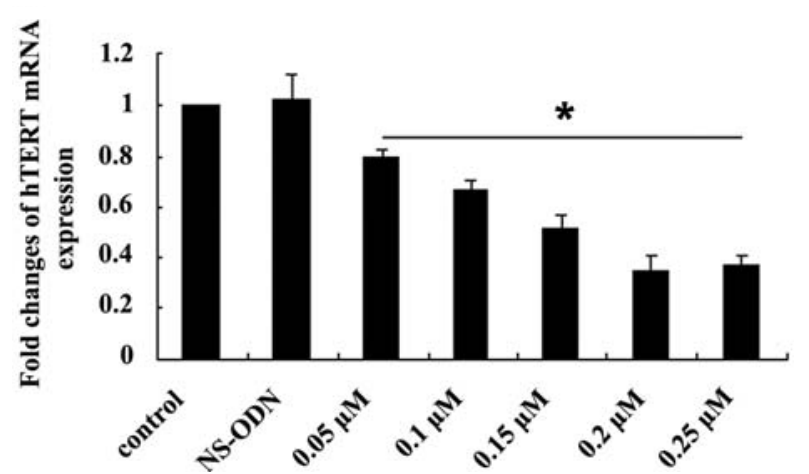

Figure 1. Effect of hTERT antisense oligonucleotides on the expression of hTERT mRNA in (A) BxPC-3 and (B) panc1 cells. Fold changes are the relative gene expression after treatment with increasing concentrations of AS-ODN or NS-ODN for $24 \mathrm{~h}$ compared to the oligofectamine-treated control. ${ }^{*} \mathrm{P}<0.05$ vs. the oligofectamine-treated control.

(FITC) Apoptosis Detection kit (Invitrogen) according to the manufacturer's instructions. Briefly, cells were plated on a 60-mm Petri dish and transfected with AS-ODN or NS-ODN at $0.2 \mu \mathrm{M}$ for 3 transfections. On the second day after the third or fifth transfection, the cells were collected and resuspended in $500 \mu \mathrm{l}$ binding buffer and $5 \mu \mathrm{l}$ Annexin-V-FITC. Propidium iodide $(5 \mu \mathrm{l})$ was added. Analysis was performed using a flow cytometer (FACScalibur, Becton-Dickinson, Franklin Lakes, NJ, USA).

Cell cycle analysis. Analysis of the cell cycle was performed using a Cycle Test plus DNA reagent kit (Becton-Dickinson). Briefly, on the second day after the third transfection with AS-ODN, cells were harvested, washed twice and stained with $25 \mu \mathrm{g} / \mathrm{ml}$ propidium iodide solution. The fluorescence of the stained cells was analysed using a flow cytometer (FACScalibur, Becton-Dickinson).

A minimum of $1 \times 10^{4}$ events was measured for each sample. The percentage of cells in different phases of the cell cycle was established on DNA plots using CellFit software according to the sum of broadened rectangles model (Becton-Dickinson).

Statistical methods. Values are expressed as the means \pm standard deviations. Statistical comparison was performed using the Student's t-test. $\mathrm{p}<0.05$ was considered statistically significant.

\section{Results}

hTERT antisense oligodeoxynucleotides down-regulate hTERT $m R N A$ expression and telomerase activity in pancreatic cancer BXPC-3 and panc-1 cell lines. We first examined the level of hTERT mRNA expression and telomerase activity in BxPC-3 and panc-1 using quantitative RT-PCR and TRAPsilver staining assay. The expression level of hTERT mRNA was found to be 2.4-fold higher in panc-1 cells compared to BxPC-3 cells. ( $\mathrm{t}=5.05, \mathrm{p}=0.007)$. According to the results of quantitative RT-PCR, the level of telomerase activity was also higher in panc-1 parental cells compared to BxPC-3 parental cells $(\mathrm{p}<0.05)$. We further examined whether hTERT AS-ODN could down-regulate the expression level of hTERT mRNA in the cell lines. As shown in Fig. 1, hTERT mRNA expression was decreased by AS-ODN in the cell lines in a dose-dependent manner (from 0.05 to $0.2 \mu \mathrm{M}$ ). Treatment with $0.2 \mu \mathrm{M}$ hTERT AS-ODN for $24 \mathrm{~h}$ acheived the maximum down-regulation of hTERT mRNA: 28.76 and $35.02 \%$ in BxPC-3 and panc- 1 cells, respectively, relative to the oligofectamine-treated control. Further dose escalation to $0.25 \mu \mathrm{M}$ did not result in more pronounced down-regulation. Thus, $0.2 \mu \mathrm{M}$ AS-ODN was selected for subsequent analysis. The NS-ODN control sequence was not found to downregulate hTERT mRNA expression levels in either of the cell lines. Additionally, we examined the effect of suppressing hTERT mRNA on telomerase activity. According to the results of quantitative RT-PCR, NS-ODN control cells exhibited significant telomerase activity, equal to that of the oligofectamine-treated control cells, whereas $0.2 \mu \mathrm{M}$ AS-ODN clones expressed significantly decreased levels of telomerase activity in the cell lines (Fig. 2) at $24 \mathrm{~h}$ as indicated by the TRAP-silver staining assay.

Effects of hTERT antisense oligodeoxynucleotides on cell proliferation in pancreatic cancer BXPC-3 and panc-1 cell lines. We next investigated whether the down-regulation of hTERT mRNA and telomerase activity could affect cell proliferation in the cell lines. Multiple consecutive transfection cycles (up to five) were performed. After the first transfection, almost no inhibition of cell proliferation was observed. On the second transfection, a reduction in cell viability was achieved in BxPC-3 cells in comparison with the oligofectamine treated control $(\mathrm{p}<0.05)$, compared to an only morderate inhibition in panc-1 cells. Multiple consecutive transfections with $0.2 \mu \mathrm{M}$ hTERT AS-ODN resulted in futher inhibition of cell proliferation. This suggests that the down-regulation of hTERT mRNA or telomerase activity could result in the inhibition of cell proliferation.

Effects of hTERT antisense oligodeoxynucleotides on colony formation ability in pancreatic cancer BxPC-3 and panc- 1 cell lines. To further investigate the effect of hTERT AS-ODN on cell growth, colony formation assays were performed in the two cells lines. The ability of isolated cells to proliferate and generate colonies was clearly reduced in the cells after three transfections (Fig. 4). In particular, BxPC-3 cells transfected with AS-ODN showed a remarkable decrease of $\geq 50 \%$ in the relative colony number. Furthermore, colonies arising from 
A

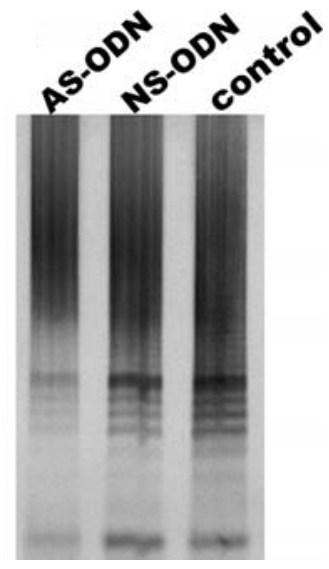

C

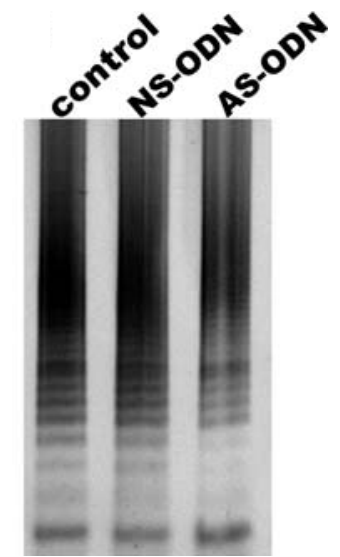

B

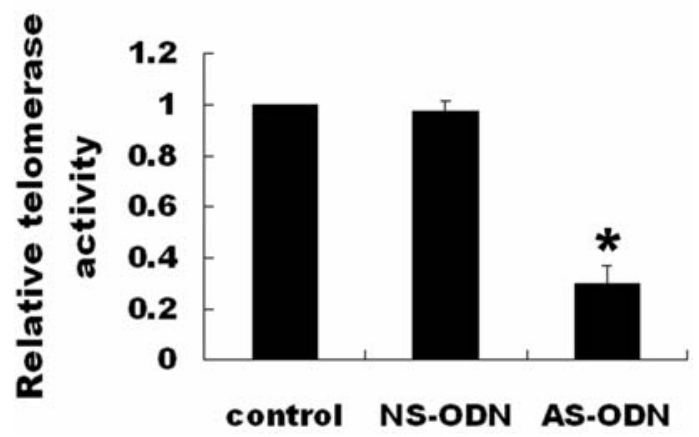

D

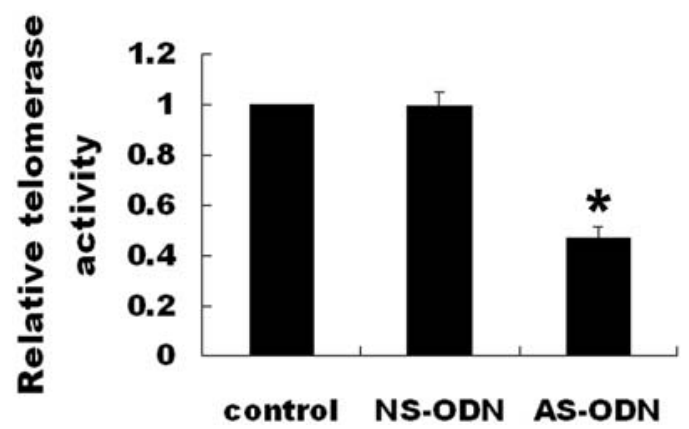

Figure 2. Inhibition of telomerase activity by hTERT antisense oligonucleotide in the cell lines. A representative telemetric repeat and amplification protocol experiment revealed telomerase activity in (A) BxPC-3 and (C) panc-1 cells. Telomerase activity was quantified by measuring the total density signal of telomerase ladder bands and the relative telomerase activity in (C) BxPC-3 and (D) panc-1 cells normalized to the untreated control cells. Data represent the mean values \pm standard deviation of at least three independent experiments. ${ }^{*} \mathrm{P}<0.05$ vs. the untreated control.

AS-ODN-treated cells were smaller than colonies originating from NS-ODN-treated cells.

hTERT antisense oligodeoxynucleotide altered cell cycle distribution and induced apoptosis in pancreatic cancer BXPC-3 and panc-1 cell lines. We further examined whether the down-regulation of hTERT mRNA and telomerase activity can alter cell cycle distribution and induce apoptosis. The analysis of cell cycle distribution showed that the number of cells in the $\mathrm{S}$ phase was decreasd and the number of cells in the G0/G1 phase was increased in the AS-ODN-transfected pancreatic cancer cells (Fig. 5). We then detected the apoptosis rates in both cells. As shown in Fig. 6, on the third transfection with $0.2 \mu \mathrm{M}$ AS-ODN, the percentage of early apoptosis in BxPC-3 and panc- 1 cells was 22.6 and $16.9 \%$, respectively. With the fifth transfection, the early apoptosis rates in BxPC-3 and panc- 1 cells increased by up to 40.75 and $28.2 \%$, respectively. The same concentration of NS-ODN control sequence did not have an influence on cell cycle distribution and resulted in a similar percentage of early apoptosis in parental cells, suggesting that the inhibition of hTERT mRNA and telomerase activity could induce cell cycle arrest and apoptosis in both cell lines. However, BxPC-3 cells were more sensitive to AS-ODN than panc-1 cells.

\section{Discussion}

In the present study, we evaluated the effect of antisense hTERT gene therapy on tumor growth in the human BxPC-3 and panc-1 pancreatic cancer cell lines in vitro. We initially demonstrated that the level of hTERT mRNA expression and telomerase activity was higher in panc-1 cells than in BxPC-3 cells, and that an antisense oligodeoxynucleotide complementary to the translation region of hTERT mRNA inhibited the expression of hTERT mRNA and telomerase activity in both cell lines. Subsequently, we showed that antisense hTERT inhibited cell proliferation in a relatively short period of time, mainly arresting the cell cycle at the G0/G1 phase. BXPC- 3 cells were more sensitive than panc- 1 cells to hTERT AS-ODN. These results suggest that the rapid anti-proliferative effect of antisense hTERT therapy in human pancreatic cancer may be independent of telomere shortening.

The activation of telomerase is a critical event in cell immortalization and tumorgenesis, and the up-regulation of human telomerase reverse transcriptase (hTERT) mRNA expression is in turn a key step in the activation of telomerase $(5,22,23)$. Previous studies have indicated that telomerase activity is strongly correlated with an abundance of hTERT mRNA but not of hTER (23-25), and that ectopic expression 
A

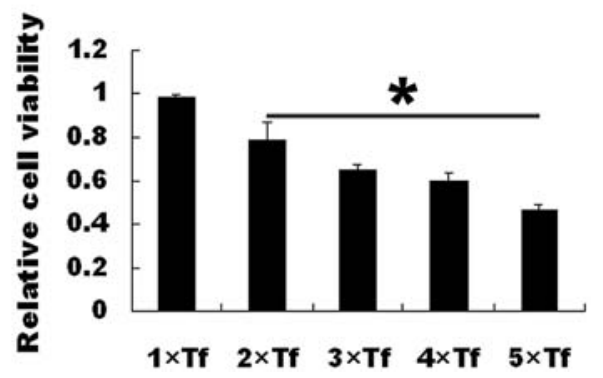

B

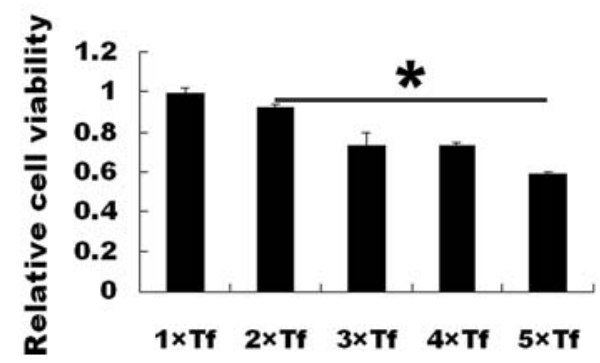

Figure 3. Effects of hTERT antisense oligonucleotides on the cell viability of (A) BxPC-3 and (B) panc-1 cells. Cell viability was dependent of the number of consecutive transfections. The relative cell viability normalized to the oligofectamine-treated controls is displayed. Data represent the mean values \pm standard deviation of at least three independent experiments. ${ }^{*} \mathrm{P}<0.05$ vs. the oligofectamine-treated control.

A



B

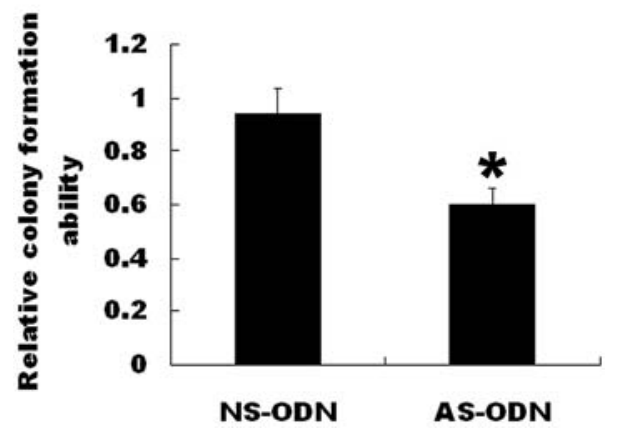

Figure 4. Colony formation ability in (A) BxPC-3 and (B) panc-1 cells. The AS-ODN-transfected cells showed much fewer colonies than the NS-ODNtransfected cells. The relative colony formation ability normalized to the oligofectamine-treated control is displayed. Data represent the mean values \pm standard deviation of at least three independent experiments. ${ }^{*} \mathrm{P}<0.05$ vs. the oligofectamine-treated control.

A

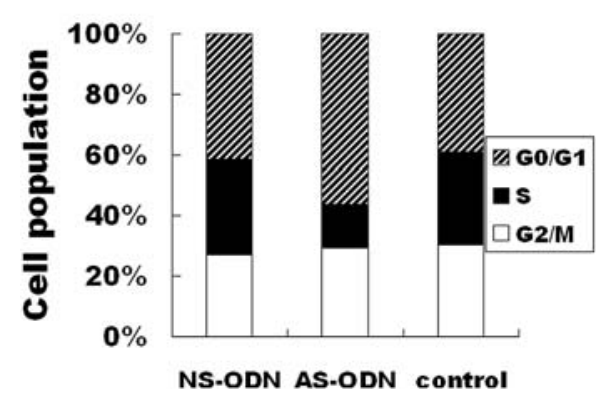

B



Figure 5. Changes in the cell-cycle distribution of (A) BxPC-3 or (B) panc-1 cells. An analysis of cell cycle distribution revealed that the number of cells in the $\mathrm{S}$ phase was decreased and the number of cells in the G0/G1 phase was increased in AS-ODN-transfected cells.

of hTERT in somatic cells is sufficient to restore telomerase activity $(8,26-28)$. Other reports suggest that the downregulation of hTERT expression or the expression of dominantnegative hTERT could inhibit telomerase activity $(13,29-33)$. For the present experiments, we selected two pancreatic cancer cell lines, BxPC-3 and panc-1, which are respectively relatively sensitive and resistant to gemcitabine, the first line reference treatment for pancreatic cancer patients. Apparently, the higher the level of hTERT mRNA and telomerase activity, the more resistant the cancer cells were to gemcitabine (data not shown). We then demonstrated that treating the pancreatic cancer cells with hTERT AS-ODN decreased the level of hTERT mRNA expression in the cell lines in a dose-dependent manner (from 0.05 to $0.2 \mu \mathrm{M}$ ), and that transfection with $0.2 \mu \mathrm{M}$ hTERT AS-ODN for $24 \mathrm{~h}$ acheived the maximum down-regulation of hTERT mRNA in both lines. According to the results of quantitative RT-PCR, single transfection with $0.2 \mu \mathrm{M}$ AS-ODN was capable of down-regulating telomerase activity by 0.3 - and 0.47 -fold in BxPC-3 and panc- 1 cells, respectively, relative to the oligofectamine-treated control. This suggests that hTERT AS-ODN is an appropriate agent for the down-regulation of telomerase activity in cancer cells. 



Figure 6. hTERT antisense oligodeoxynucleotide-induced apoptosis in (A) BxPC-3 and (B) panc-1 cells. Increasing the number of transfections further increased the apoptosis rate from 22.6 to $40.75 \%$ in BxPC-3 cells, and from 16.9 to $28.2 \%$ in panc-1 cells. (A1 and B1) The cell lines treated without drug administration. (A2 and B2) The cell lines transfected 3 times consecutively with $0.2 \mu \mathrm{M}$ AS-ODN. (A3 and B3) The cell lines transfected 5 times consecutively with $0.2 \mu \mathrm{M}$ AS-ODN. Early apoptotic cells were defined as Annexin V-positive, propidium iodide-negative cells.

Recent studies suggest that hTERT can maintain cell survival and proliferation by means of a telomere-elongating (8) or telomere-capping process of the enzyme $(34,35)$. As a consequence, telomerase inhibitory approaches based on interference with hTERT expression might affect tumor cell proliferation by inhibiting one or both of the above functions. As for the inhibition of telomere-elongating function, most studies have demonstrated that cancer cell death was observed only after many cell divisions over a long lagphase before the telomeres were reduced to critical lengths $(14,36)$. While it has also been demonstrated that the downregulation of hTERT by treatment with antisense oligonucleotides or hammerhead ribozyme rapidly induces programmed cell death in human tumor cells, independent of the telomere-elongating function $(13,37,38)$, these rapid effects appear to be caused by deficient telomere capping $(9,34,35,37,38)$. In the present study, after the first transfection with $0.2 \mu \mathrm{M}$ AS-ODN, almost no inhibition of cell proliferation was found in either of the cell lines, while multiple consecutive transfections with the same concentration of AS-ODN resulted in a continuous reduction in cell viability and the significant inhibition of colony formation ability. In particular, BxPC-3 cells transfected with AS-ODN showed a remarkable decrease of $\geq 50 \%$ in the relative colony number. Multiple tranfections with hTERT AS-ODN further increased apoptosis rates in both cells.

Our results are partially consistent with those of the abovementioned studies, though we did not observe the immediate inhibition of cell proliferation in the AS-ODNtransfected cells. It can be speculated that one single transfection with AS-ODN was not enough to interfere with the telomere enlongating function or capping process of hTERT in the cells. However, the observed efficient inhibition of cell proliferation over a relatively short time period may be mediated by the telomere uncapping process, not by telomere shortening. In fact, as human cells reduce their telomere length by 50-100 base pairs per cell division, a long lag phase is required before growth arrest can be obtained, even in tumor cells with relatively short telomeres (39). The consecutive monitoring of telomere length or telomere state will be the subject of our next study.

It is well known that cells in the $\mathrm{S}$ phase possess the highest proliferating capacity, while cells in G0/G1 phase possesses the lowest one. Telomerase activity is also regulated in a cell cycle-dependent manner (40). For example, telomerase activity is maximally detected in the $\mathrm{S}$ phase, but is barely detectable in the G2/M phase (41). The analysis of cell cycle distribution in our study showed that AS-ODN mainly arrested the cell cycle in the G0/G1 phase. Thus, we speculate that the inhibition of cell proliferation using hTERT AS-ODN in our study may be mediated by the down-regulation of telomerase through the arresting of the cell cycle in the G0/G1 phase.

In conclusion, our results indicate that hTERT AS-ODN down-regulates the expression of hTERT mRNA and telomerase activity, and arrests cancer cell growth over a relatively short period of time. The most likely mechanism behind this is the telomere uncapping process, which arrests cell cycle progression and results in the inhibition of cell proliferation or apoptosis. These findings validate an antisense oligonucleotide approach to hTERT inhibition therapy in pancreatic cancer cells, and should be further explored in vivo. 


\section{Acknowledgements}

This study was supported by the Science and Technology Planning Project of Changzhou, Jiangsu Province, China (CS2004214).

\section{References}

1. Li D, Xie K, Wolff R and Abbruzzese JL: Pancreatic cancer. Lancet 363: 1049-1057, 2004.

2. Bray F, Sankila R, Ferlay J and Parkin DM: Estimates of cancer incidence and mortality in Europe in 1995. Eur J Cancer 38: 99-166, 2002.

3. Beger HG, Rau B, Gansauge F, Poch B and Link KH: Treatment of pancreatic cancer: challenge of the facts. World J Surg 27: 1075-1084, 2003.

4. Counter CM, Avilion AA, LeFeuvre CE, Harley CB, West MD, Ho PL and Bacchetti S: Telomere shortening associated with chromosome instability is arrested in immortal cells which express telomerase activity. EMBO J 11: 1921-1929, 1992.

5. Kim NW, Piatyszek MA, Prowse KR, Harley CB, West MD, Ho PL, Coviello GM, Wright WE, Weinrich SL and Shay JW: Specific association of human telomerase activity with immortal cells and cancer. Science 266: 2011-2015, 1994.

6. Hiyama K, Hiyama E, Ishioka S, Yamakido M, Inai K, Gazdar AF, Piatyszek MA and Shay JW: Telomerase activity in small-cell and non-small-cell lung cancers. J Natl Cancer Inst 87: 895-902, 1995 .

7. Suehara N, Mizumoto K, Muta T, Tominaga Y, Shimura H, Kitajima S, Hamasaki N, Tsuneyoshi M and Tanaka Ml: Telomerase elevation in pancreatic ductal carcinoma compared to nonmalignant pathological states. Clin Cancer Res 3: 993-998, 1997.

8. Bodnar AG, Ouellette M, Frolkis M, Holt SE, Chiu CP Morin GB, Harley CB, Shay JW, Lichtsteiner S and Wright WE Extension of life-span by introduction of telomerase into norma human cells. Science 279: 349-352, 1998.

9. Chan SW and Blackburn EH: New ways not to make ends meet: telomerase, DNA damage proteins and heterochromatin. Oncogene 21: 553-563, 2002.

10. Chen XJ, Zheng W, Chen LL, Chen ZB and Wang SQ: Telomerase antisense inhibition for the proliferation of endometrial cancer in vitro and in vivo. Int J Gynecol Cancer 16: 1987-1993, 2006.

11. Tao Z, Chen S, Wu Z, Xiao B, Liu J and Hou W: Targeted therapy of human laryngeal squamous cell carcinoma in vitro by antisense oligonucleotides directed against telomerase reverse transcriptase mRNA. J Laryngol 19: 92-96, 2005.

12. Folini M, Brambilla C, Villa R, Gandellini P, Vignati S, Paduano F, Daidone MG and Zaffaroni N: Antisense oligonucleotide-mediated inhibition of hTERT, but not hTERC, induces rapid cell growth decline and apoptosis in the absence of telomere shortening in human prostate cancer cells. Eur J Cancer 41: 624-634, 2005.

13. Kraemer K, Fuessel S, Schmidt U, Kotzsch M, Schwenzer B Wirth MP and Meye A: Antisense-mediated hTERT inhibition specifically reduces the growth of human bladder cancer cells. Clin Cancer Res 9: 3794-3800, 2003.

14. Teng L, Specht MC, Barden CB and Fahey TJ 3rd: Antisense hTERT inhibits thyroid cancer cell growth. J Clin Endocrinol Metab 88: 1362-1366, 2003.

15. Qian X, Cheng J, Chen A, Wang Y, Tao Y, Cao J and Feng Z: Long-term effects of short hairpin RNA-targeted human telomerase reverse transcriptase on suppression of SGC-7901 cell proliferation by inhibition of telomerase activity. Oncol Rep 19: 575-581, 2008.

16. Shen Y, Zhang YW, Zhang ZX, Miao ZH and Ding J: hTERTtargeted RNA interference inhibits tumorigenicity and motility of HCT116 cells. Cancer Biol Ther 7: 228-236, 2008.

17. Chen SM, Tao ZZ, Hua QQ, Xiao BK, Xu Y, Wang Y and Deng YQ: Inhibition of telomerase activity in cancer cells using short hairpin RNA expression vectors. Cancer Invest 25: 691-698, 2007.

18. De Souza Nascimento P, Alves G and Fiedler W: Telomerase inhibition by an siRNA directed against hTERT leads to telomere attrition in HT29 cells. Oncol Rep 16: 423-428, 2006.

19. Folini M, Bandiera R, Millo E, Gandellini P, Sozzi G, Gasparini P, Longoni N, Binda M, Daidone MG, Berg K and Zaffaroni N: Photochemically enhanced delivery of a cell-penetrating peptide nucleic acid conjugate targeting human telomerase reverse transcriptase: effects on telomere status and proliferative potential of human prostate cancer cells. Cell Prolif 40: 905-920, 2007.
20. Hayashidani Y, Hiyama E, Murakami Y and Sueda T: Attenuation of telomerase activity by hammerhead ribozymes targeting human telomerase RNA and telomerase reverse transcriptase in pancreatic carcinoma cells. Hiroshima J Med Sci 54: 21-27, 2005.

21. Livak KJ and Schmittgen TD: Analysis of relative gene expression data using real-time quantitative PCR and the 2(-Delta Delta C(T)) Method. Methods 25: 402-408, 2001.

22. Shay JW and Bacchetti S: A survey of telomerase activity in human cancer. Eur J Cancer 33: 787-791, 1997.

23. Meyerson M, Counter CM, Eaton EN, Ellisen LW, Steiner P, Caddle SD, Ziaugra L, Beijersbergen RL, Davidoff MJ, Liu Q, Bacchetti S, Haber DA and Weinberg RA: hEST2, the putative human telomerase catalytic subunit gene, is up-regulated in tumor cells and during immortalization. Cell 90: 785-795, 1997.

24. Avilion AA, Piatyszek MA, Gupta J, Shay JW, Bacchetti S and Greider CW: Human telomerase RNA and telomerase activity in immortal cell lines and tumor tissues. Cancer Res 56: 645-650, 1996.

25. Nakamura TM, Morin GB, Chapman KB, Weinrich SL, Andrews WH, Lingner J, Harley CB and Cech TR: Telomerase catalytic subunit homologs from fission yeast and human. Science 277: 955-959, 1997.

26. Nakayama J, Tahara H, Tahara E, Saito M, Ito K, Nakamura H, Nakanishi T, Tahara E, Ide T and Ishikawa F: Telomerase activation by hTRT in human normal fibroblasts and hepatocellular carcinomas. Nat Genet 18: 65-68, 1998.

27. Vaziri H and Benchimol S: Reconstitution of telomerase activity in normal human cells leads to elongation of telomeres and extended replicative life span. Curr Biol 8: 279-282, 1998.

28. Counter CM, Meyerson M, Eaton EN, Ellisen LW, Caddle SD, Haber DA and Weinberg RA: Telomerase activity is restored in human cells by ectopic expression of hTERT (hEST2), the catalytic subunit of telomerase. Oncogene16: 1217-1222, 1998.

29. Bae-Jump VL, Zhou C, Gehrig PA, Whang YE and Boggess JF: Rapamycin inhibits hTERT telomerase mRNA expression, independent of cell cycle arrest. Gynecol Oncol 100: 487-494, 2006.

30. Natarajan S, Chen Z, Wancewicz EV, Monia BP and Corey DR: Telomerase reverse transcriptase (hTERT) mRNA and telomerase RNA (hTR) as targets for downregulation of telomerase activity. Oligonucleotides 14: 263-273, 2004.

31. Pallini R, Sorrentino A, Pierconti F, Maggiano N, Faggi R, Montano N, Maira G, Larocca LM, Levi A and Falchetti ML: Telomerase inhibition by stable RNA interference impairs tumor growth and angiogenesis in glioblastoma xenografts. Int J Cancer 118: 2158-2167, 2006.

32. Hahn WC, Stewart SA, Brooks MW, York SG, Eaton E, Kurachi A, Beijersbergen RL, Knoll JH, Meyerson M and Weinberg RA: Inhibition of telomerase limits the growth of human cancer cells. Nat Med 5: 1164-1170, 1999.

33. Zhang X, Mar V, Zhou W, Harrington L and Robinson MO: Telomere shortening and apoptosis in telomerase-inhibited human tumor cells. Genes Dev 13: 2388-2399, 1999

34. Blackburn EH: Telomere states and cell fates. Nature 408: 53-56, 2000.

35. Cao Y, Li H, Deb S and Liu JP: TERT regulates cell survival independent of telomerase enzymatic activity. Oncogene 21 : 3130-3138, 2002.

36. Nakamura M, Masutomi K, Kyo S, Hashimoto M, Maida Y, Kanaya T, Tanaka M, Hahn WC and Inoue M: Efficient inhibition of human telomerase reverse transcriptase expression by RNA interference sensitizes cancer cells to ionizing radiation and chemotherapy. Hum Gene Ther 16: 859-868, 2005.

37. Saretzki G, Ludwig A, von Zglinicki T and Runnebaum IB: Ribozyme-mediated telomerase inhibition induces immediate cell loss but not telomere shortening in ovarian cancer cells. Cancer Gene Ther 8: 827-834, 2001.

38. Hao ZM, Luo JY, Cheng J, Li L, He D, Wang QY and Yang GX: Intensive inhibition of hTERT expression by a ribozyme induces rapid apoptosis of cancer cells through a telomere lengthindependent pathway.Cancer Biol Ther 4: 1098-1103, 2005.

39. Keith WN, Evans TRJ and Glasspool RM: Telomerase and cancer: time to move from a promising target to a clinical reality. J Pathol 195: 404-414, 2001.

40. Zhu X, Kumar R, Mandal M, Sharma N, Sharma HW, Dhingra U, Sokoloski JA, Hsiao R and Narayanan R: Cell cycle-dependent modulation of telomerase activity in tumor cells. Proc Natl Acad Sci USA 93: 6091-6095, 1996.

41. Holt SE, Wright WE and Shay JW: Regulation of telomerase activity in immortal cell lines. Mol Cell Biol 16: 2932-2939, 1996. 